\title{
A BIOASSAY FOR HETERODERA SPP. WITHOUT COUNTING CYSTS OR LARVAE
}

\author{
BY \\ F. G. W. JONES \& MARGARET C. GANDER \\ Rothamsted Experimental Station, Harpenden, England
}

\begin{abstract}
Cyst batches of approximately equal size for use in bioassays can be set up with a simple pipette and the larvae that hatch from them can be assessed by absorptiometry, which saves the time and tedium of counting both cysts and larvae. In an experiment on the use of charcoal to recover the hatching factor from potato root diffusate, the results of bioassays by this method agreed well with those based on counts. The interpretation of data is discussed.
\end{abstract}

The hatching test devised by Fenwick \& Widowson (1958) for cysts of Heterodera rostocbiensis $W$. has been used routinely for over 10 years at Rothamsted and elsewhere in work on the hatching factor by Todd and his collaborators (see Carroll, Heyes, Johnson \& Todd 1958), Widdowson \& Wiltshire (1958), Clarke (1960) and has been modified for use with other Heterodera spp. by Winslow (see Carroll 1958).

Essentially the method consists of plying replicated batches of 100 or more cysts with dilutions of test solutions and comparing the hatch-dilution curves obtained with a standard curve from dilutions of stored potato root diffusate. Because the hatch from cysts varies and the stored diffusate slowly deteriorates (fig. 1) a standard curve must be included in each series of chemicals tested at one time. The hatch is continued for 3 weeks, the test solutions are changed weekly and larvae are counted in a counting slide from $1 \mathrm{ml}$ or smaller aliquots of suitably diluted suspensions. The method is laborious and time-consuming but is satisfactory. The work described below follows Fenwick's method but discards counting in the weekly routine of setting up batches of cysts and estimating the number of larvae produced. When hatching proceeds normally, the bioassay can be shortened from 21 to 10 days.

\section{Preparing cyst batches}

Fenwick (1951) tried to replace cyst counting by weighing batches on a special balance, but this is almost as tedious as counting. After experimentation with several other methods, the simple pipette shown in fig. 2 was made. Cysts are placed in a beaker with enough water to form a thick suspension. A vibrator is introduced and its amplitude and frequency adjusted to give thorough and vigorous mixing. The pipette is inserted and, by squeezing and releasing the bulb, cysts 
are drawn into the small plastic measure on the end and then expelled into a watch glass together with water. Care must be taken that the measure is filled and that any excess of cysts beyond the end is removed before the measure is emptied. The cysts used may be round or lemon-shaped or mixed with debris,

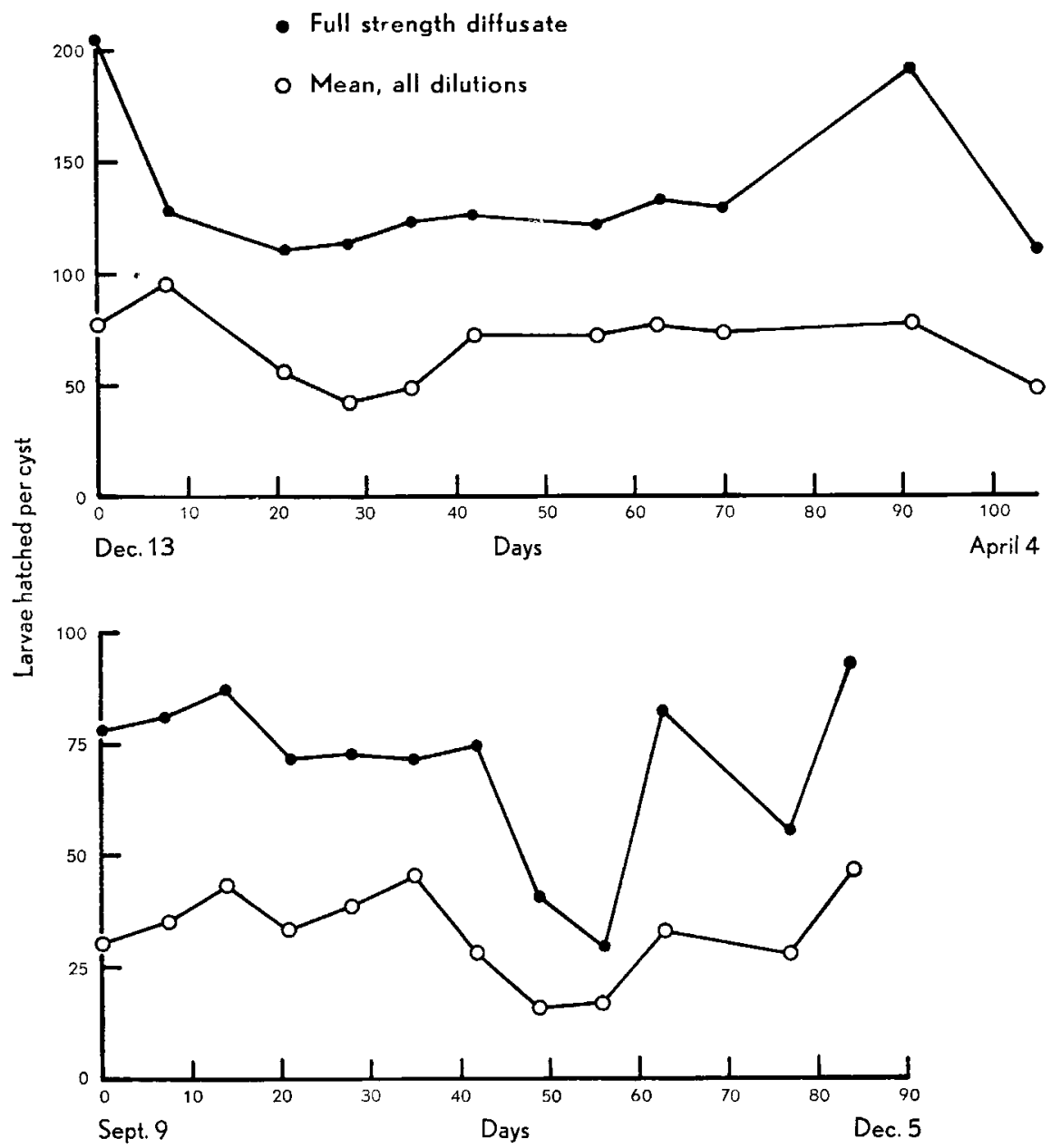

Fig. 1. Variations in hatch from two different batches of cysts and diffusate. The tests were set up on each occasion in the same way and incubated at $24^{\circ} \mathrm{C}$. Upper graph 1957 cysts (237 eggs/cyst) and 1959 diffusate. Lower graph 1959 cysts (114 eggs/g) and 1960 diffusate. ... hatch from fullstrength diffusate, each point the mean hatch from two batches of 250 cysts. o- o hatch from all dilutions, each point the mean of fourteen batches of 250 cysts.

provided the debris is not much larger than cyst size. Cysts of species sensitive to drying freshly elutriated from soil or pots can be used without being dried or exposed to heat from microscope lamps which can depress hatch (Shepherd 1962). 
Excess cysts of $H$. rostocbiensis which withstands drying well can be dried and used again several times without loss of hatching power.

The mean number of cysts per batch can be varied by altering the size of the

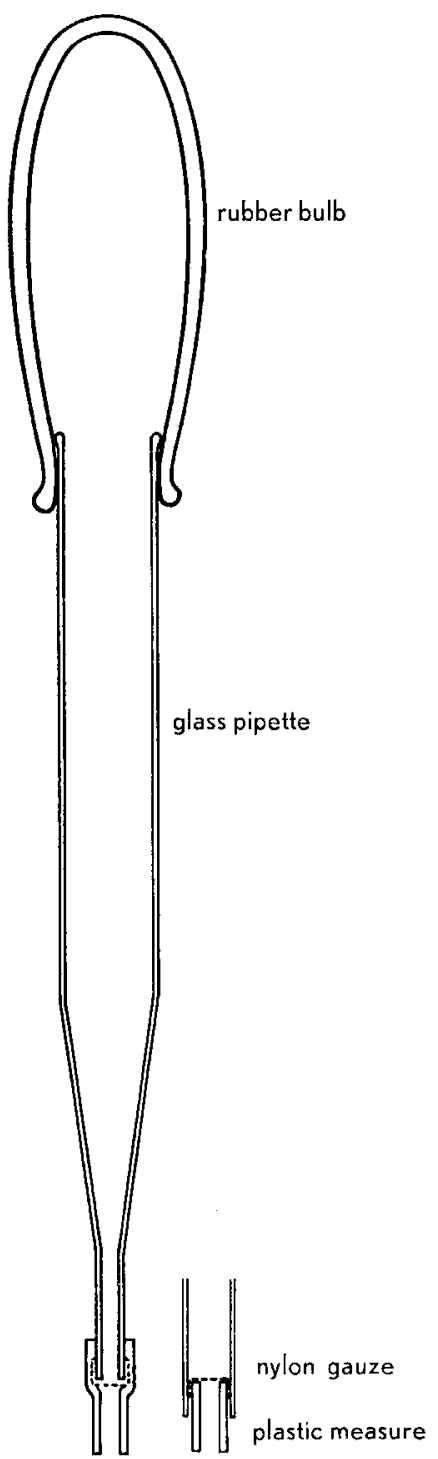

(a) (b)

Fig. 2. A simple pipette for setting up batches of cysts of approximately equal size. (a) and (b) are alternative ways of fixing the measure of which (b) is the better, giving better suction.

plastic measure. Although variability is greater than in carefully counted batches, the method avoids the gross errors from counting when the operator is tired or disturbed and total variability is about the same (Table I). Although there is a 


\section{TABle I}

Comparison of variability in cyst batches prepared by counting and by pipette

\begin{tabular}{|c|c|c|c|c|c|c|}
\hline Method & Species & $\begin{array}{l}\text { No. } \\
\text { batches }\end{array}$ & $\begin{array}{c}\text { Mean no. } \\
\text { of } \\
\text { Cysts }\end{array}$ & SD & $\%$ & $95 \%$ range \\
\hline Counting & H. rostocbiensis & 41 & 251 & \pm 16.7 & $7 \%$ & $217-284$ \\
\hline Pipette & " & 35 & 256 & \pm 19.1 & $7 \%$ & $219-293$ \\
\hline, & , & 10 & 126 & \pm 6.0 & $5 \%$ & $102-150$ \\
\hline$"$ & $\begin{array}{l}\text { H. schacbtii } \\
\text { with some debris }\end{array}$ & 20 & 103 & \pm 8.7 & $8 \%$ & $86 \cdot 120$ \\
\hline$m$ & " & 10 & 98 & \pm 7.0 & $7 \%$ & 84-112 \\
\hline$"$ & $"$ & 10 & 129 & \pm 6.7 & $5 \%$ & $116-142$ \\
\hline ” & " & 8 & 94 & \pm 8.6 & $9 \%$ & $77-111$ \\
\hline
\end{tabular}

correlation between cyst numbers and hatch, even when counting is careful and accurate, the hatch from batches varies widely: meticulous counting is thereby nullified and the time it takes wasted. Randomization of batches minimises the effects of size difference. The method outlined above is simple, takes much less time than counting, and allows larger batches and more replications to be used.

\section{Counting batched larvae}

Korsten, Sieben \& Voskuyl (1953) and Blake (1958) showed that absorptiometry could be used to count suspended nematodes. Carboxy methyl cellulose stabilises aqueous suspensions of nematodes (Blake 1958), but its use is not essential. By agitating thoroughly and working rapidly, suspensions in water are stable enough for readings of absorption, using $4 \mathrm{~cm}$ cells on a Hilger "Spekker" absorptiometer fitted with H.508 filters, to show the relationship between nematode numbers per $\mathrm{ml}$ and absorption. Fig. 3 was obtained as follows. Hatched larvae of $H$. rostochiensis were cleaned by allowing them to pass overnight through a coarse filter (Greens No. 150) into distilled water. This concentrated suspension was agitated and diluted to $3 / 4,1 / 2,1 / 4$ and $1 / 10$, and the absorption by these samples was measured using distilled water as a standard. The larvae per $\mathrm{ml}$ of the original suspension were determined by dilution counts in a Hawksley slide (Goodey 1957). A total of 1046 larvae were counted giving a Poisson standard error of \pm 32.3 and $95 \%$ fiducial limits of \pm 63.4 (i.e. $3 \%$ and $6 \%$ respectively). The calculated number per $\mathrm{ml}$ of original suspension was $6250(95 \%$ range 5875-6625) which has been used in the scale for larvae per $\mathrm{ml}$ in fig. 3. Similar graphs can be constructed for other Heterodera and Meloidogyne species.

Fixing by adding suitable volumes of concentrated formalin increased absorption slightly. $1 \mathrm{ml}$ of $0.1 \mathrm{~N}$ iodine in $\mathrm{KI}$ added to $25 \mathrm{ml}$ of suspension stained larvae rapidly and densely but increased absorption by little more than $10 \%$.

Before reading, the excess iodine was decolourised with $1 \mathrm{ml}$ of $0.1 \mathrm{~N}$ sodium thiosulphite. The increase in absorption did not compensate for the extra operations it required. 


\section{Duration of the batcbing test}

In Fenwick's method larvae are counted after 1,2 and 3 weeks. The hatch after 1 week indicates trends but is not always a reliable guide to the final results. By the end of the second week most substances tested have approached their maximum hatch and, by the end of the third, hatch is virtually complete. This does not always hold, for larvae may emerge over a longer period from newly

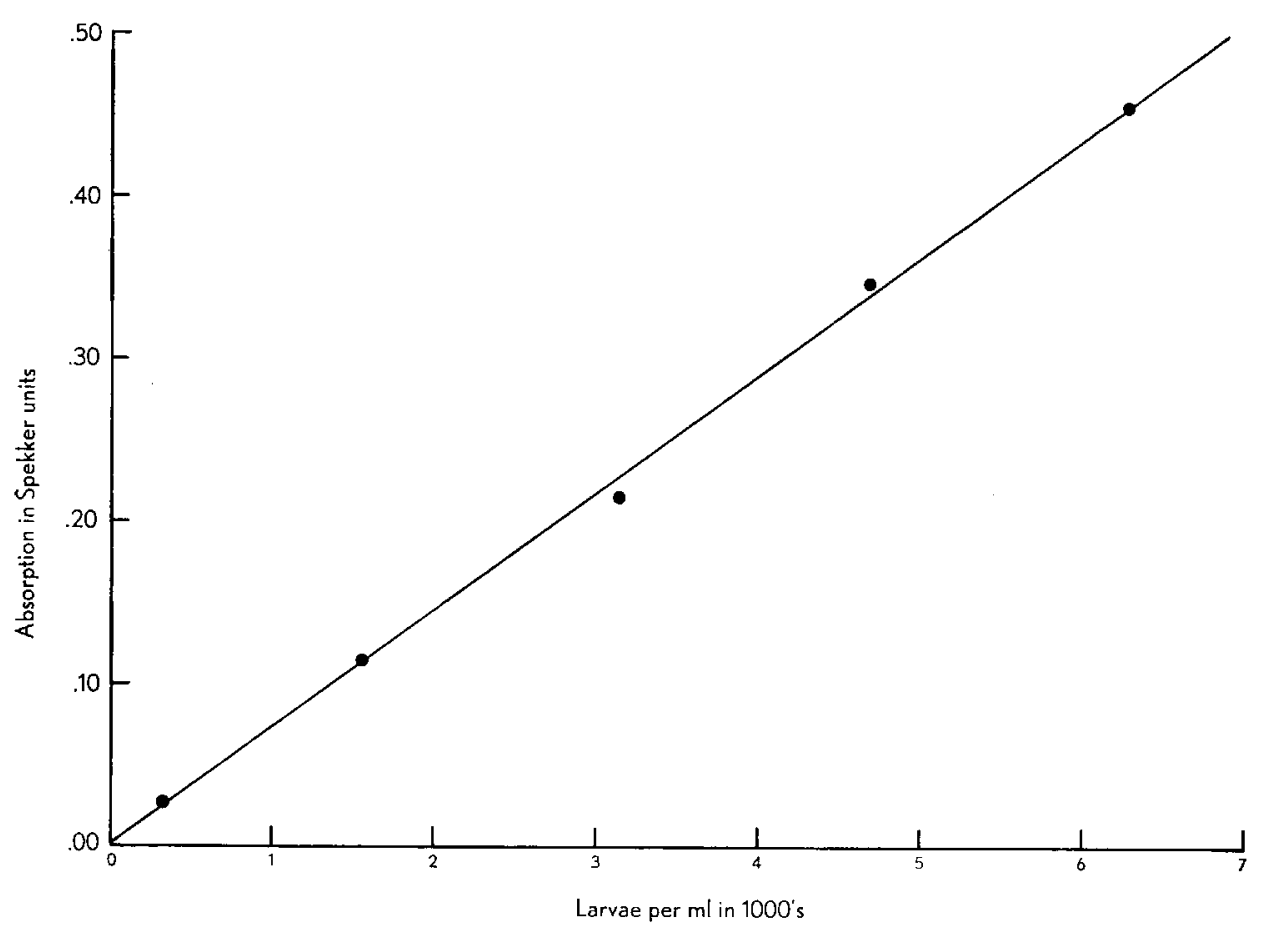

Fig. 3. The relationship between absorption and larvae per $\mathrm{ml}$ of suspension for $H$, rostochiensis.

produced cysts (Jones 1954) and the hatch from old cysts is sometimes delayed. Fig. 4 compares the hatch at the end of the first and second weeks with that at the end of the third in a series of tests on beet eelworm (results supplied by Dr. A. M. Shepherd). The inadequacy of the hatch after 1 week is shown by the scatter of the points. At the end of the second the scatter is much less. Within the second week most of the hatch occurs in the first few days, i.e. within 10 days of starting the tests. The hatch from batches of $H$. rostocbiensis was therefore counted at 10 and 20 days. Fig. 5 shows that the two counts were closely correlated, that most hatches were almost complete in 10 days and that additional hatch exceeded $20 \%$ in a few tests only, a departure not greatly in excess of experimental error. For most purposes 10-day hatches are adequate, and their use greatly speeds work on such problems as purifying hatching factors. 


\section{A complete bioassay without counting}

Test solutions were obtained from an experiment on the removal of hatching factor from raw, filtered potato root diffusate by charcoal. To $100 \mathrm{ml}$ lots of diffusate, $50,75,100,125,150,200,300$ and $400 \mathrm{mg}$ of charcoal were added and filtered off after shaking for $10 \mathrm{~min}$. The masses of charcoal were then eluted with two successive lots of $100 \mathrm{ml}$ acetone, the first containing $0.4 \mathrm{ml}$ conc. HCl. The acetone was evaporated off at $30^{\circ} \mathrm{C}$ and $14 \mathrm{~mm} \mathrm{Hg}$ in the

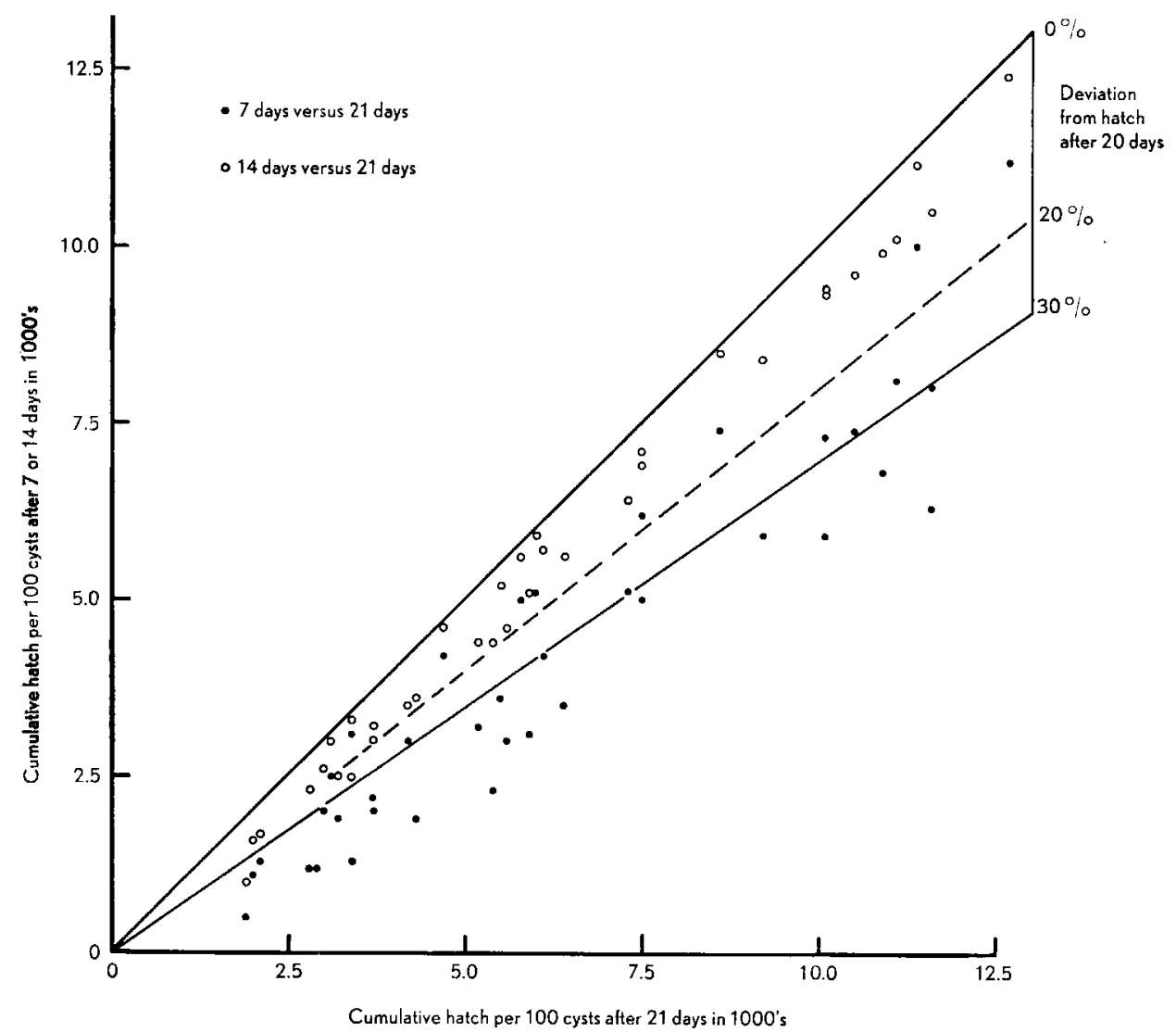

Fig. 4. The relationship between hatch of $H$. schachtii after 7 and 14 days to that after 21 days. Hatches after 7 days are more than $30 \%$ below those after 21 days but those after 14 days are mostly within $20 \%$.

presence of excess $\mathrm{CaCO}_{3}$. The residue was shaken with $100 \mathrm{ml}$ dist. water so that, were recovery complete, the hatch would equal that given by the original diffusate. Excess $\mathrm{CaCO}_{3}$ was filtered off. Dilutions of $1 / 1,1 / 4,1 / 16,1 / 64$ and 1/256 were prepared from the filtrates and eluates and from raw diffusate. The range of the standard curve was completed with diffusate further diluted to $1 / 1024$ and with two lots of distilled water to establish the water hatch. 
440 batches each containing about 256 cysts were set up with the pipette described. Vibrating the cysts suspended the dirt present as a contaminant and so the turbid liquid in each watch glass was replaced by water. After soaking for 10 days the water was removed, the test solutions added and the cysts incubated at $24^{\circ} \mathrm{C}$. After a further 10 days the test fluids and hatched larvae were drawn off and replaced. The fluid withdrawn from the five replicates in each test (about $2 \mathrm{ml}$ per replicate including rinsing) was put together into a $25 \mathrm{ml}$ graduated

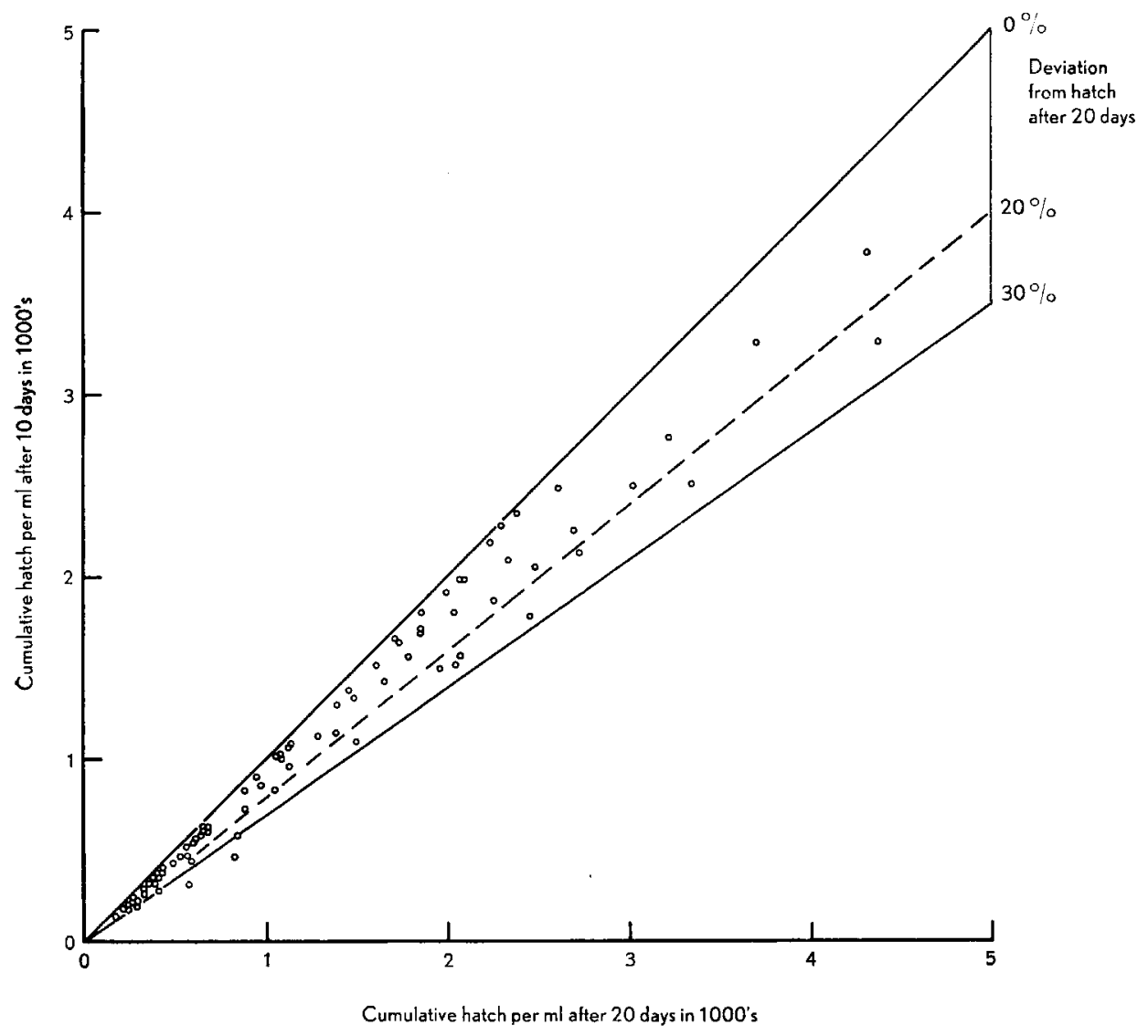

Fig. 5. The relationship between hatch of $H$. rostocbiensis after 10 days to that at 20 days. Most hatches at 10 days are within $20 \%$ of those at 20 days.

flask and made up to the mark with distilled water. After vigorous agitation, the absorption of the pooled suspensions was read off using distilled water as a standard and making an adjustment for the turbidity of the test solution. This was appreciable in the $1 / 1,1 / 4$, and $1 / 16$ dilutions but negligible in $1 / 64$ and $1 / 256$.

Dilution counts were made to monitor the absorption readings at 10 days and again at 20 days to test residual hatch (see fig. 5). Dilution-hatch curves (figs. 6 and 7) show good agreement between counts and absorption. Fig. 8 shows 
the increasing amount of factor extracted by increasing amounts of charcoal and the recovery of factor by elution. Here again absorption measurements and counts agree well. Almost all activity is removed from $100 \mathrm{ml}$ of diffusate by $200 \mathrm{mg}$ of charcoal. No clear picture emerges of the recovery by elution although two peaks between 100-200 and at $400 \mathrm{mg}$ charcoal are suggested. The results may have been confused by inhibitors absorbed by and eluted from the charcoal at

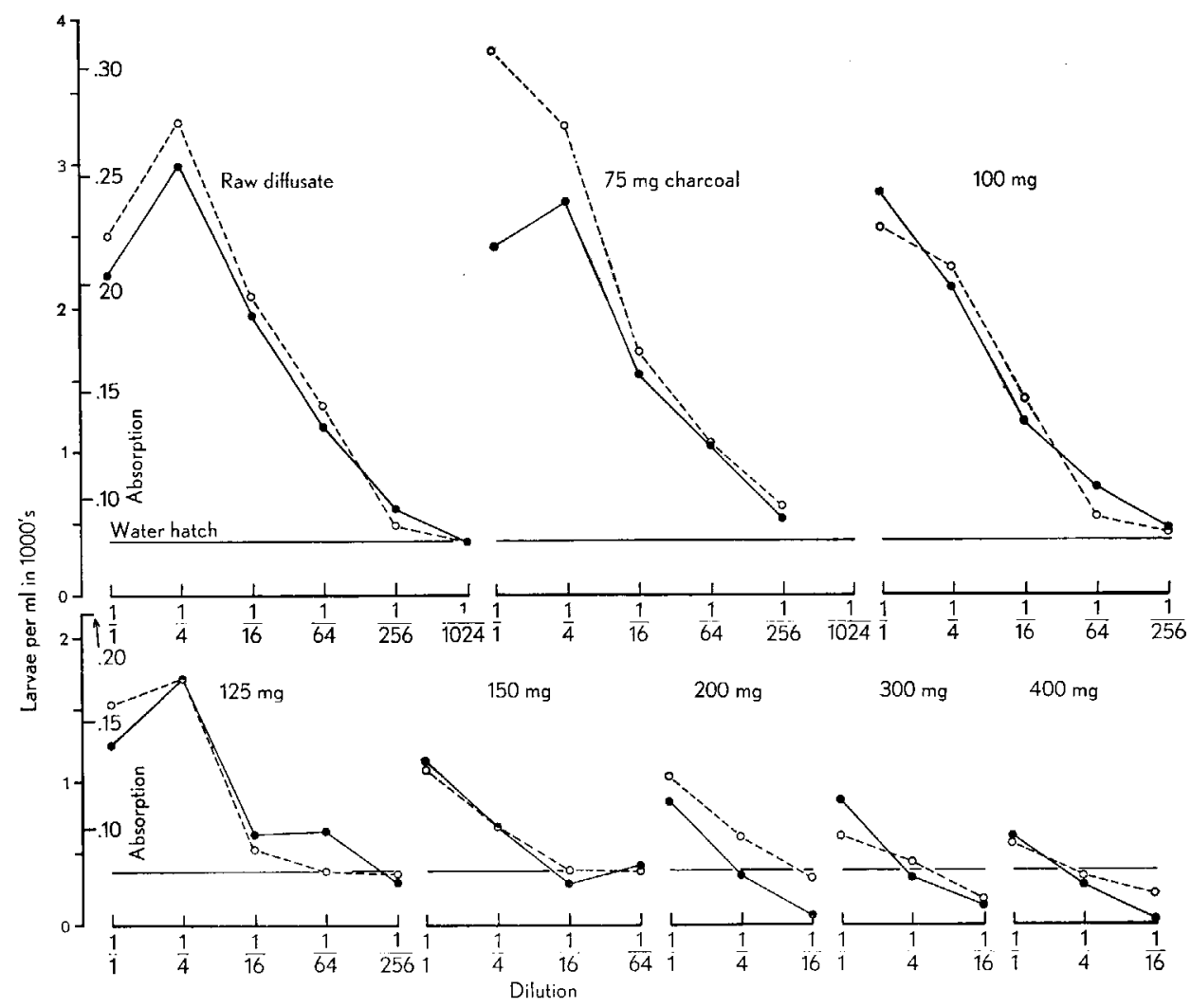

Fig. 6. Comparison of hatch-dilution curves for $100 \mathrm{ml}$ lots of raw diffusate after shaking with increasing weights of charcoal. Results from $50 \mathrm{mg}$ charcoal omitted; o-。 counts; .- absorption.

different rates from the hatching factor. Impurities in the charcoal may also have played a part. Inhibition in the 1/1 raw diffusate and in the filtrates is apparent (top graphs in Fig. 8). The dotted lines indicate the form of the curves expected.

\section{Discussion}

Estimating larval concentrations by absorptiometry avoids counting errors and is not subject to Poisson errors of the same magnitude as dilution counting. Errors arise however from extraneous material in the larval suspensions, from 
gas bubbles, and from bacteria and fungi that grow on the cyst batches. With care these errors are small but there is always some turbidity from components other than larvae. For this reason the method is not suitable for suspensions containing few larvae per $\mathrm{ml}$ for which direct counting is relatively easy. By pooling the hatch from five replicates of approximately 250 cysts each, dense suspensions were obtained which gave satisfactory readings. In routine bioassays there is much arithmetic in the calculation of larvae per $\mathrm{ml}$ and means of replicates. Absorption readings from five pooled replicates require only to be corrected

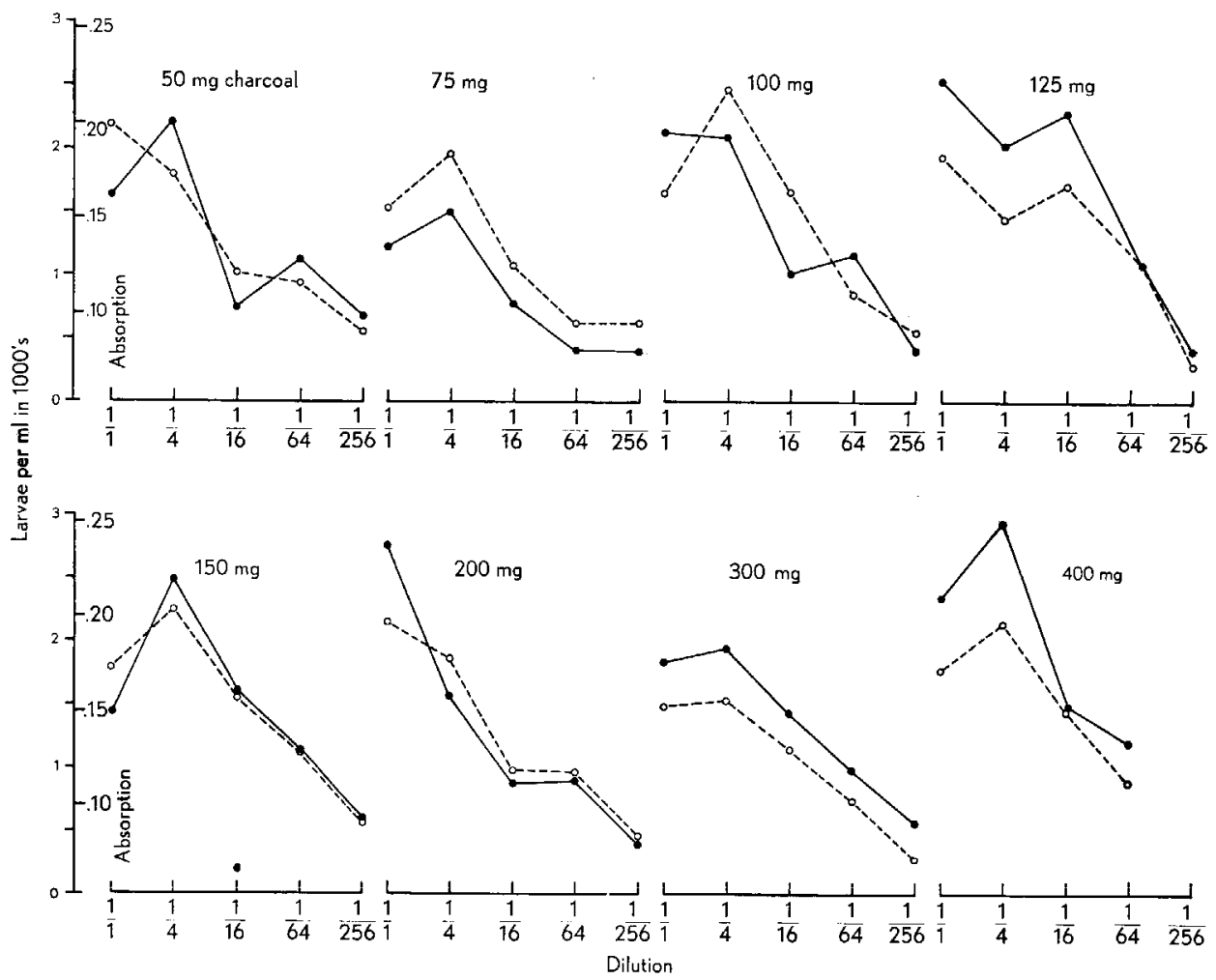

Fig. 7. Comparison of hatch-dilution curves for eluates from the separate weights of charcoal used in fig. 6. If no activity were lost and there were no inhibition all curves should be as for raw diffusate in Fig. 6.

for occasional aberrations of the absorptiometer and for the background turbidity of test solutions. Time is saved on arithmetic and mistakes are fewer. By using graduated flasks, errors of dilution are also minimised. These need not be serious in Fenwick's method when wide mouthed tubes are used, but they sometimes are.

To ease the labour of counting, Ellenby (1960) based his bioassay on only ten cysts per batch and transformed the variable hatch obtained to a logarithmic or double logarithmic scale. Although there is justification for transforming to logarithms because absolute (as opposed to relative) variability increases with 
the size of the hatch, there seems little justification for transforming to a double logarithmic scale. Both transformations of the hatch-dilution curve are in fig. 9 and neither gives a straight line as Ellenby claimed but a sigmoid curve like the arithmetic curve, deformed upwards, and variability is obscured but not overcome.

Difficulty in determining an end point for hatching activity arises because

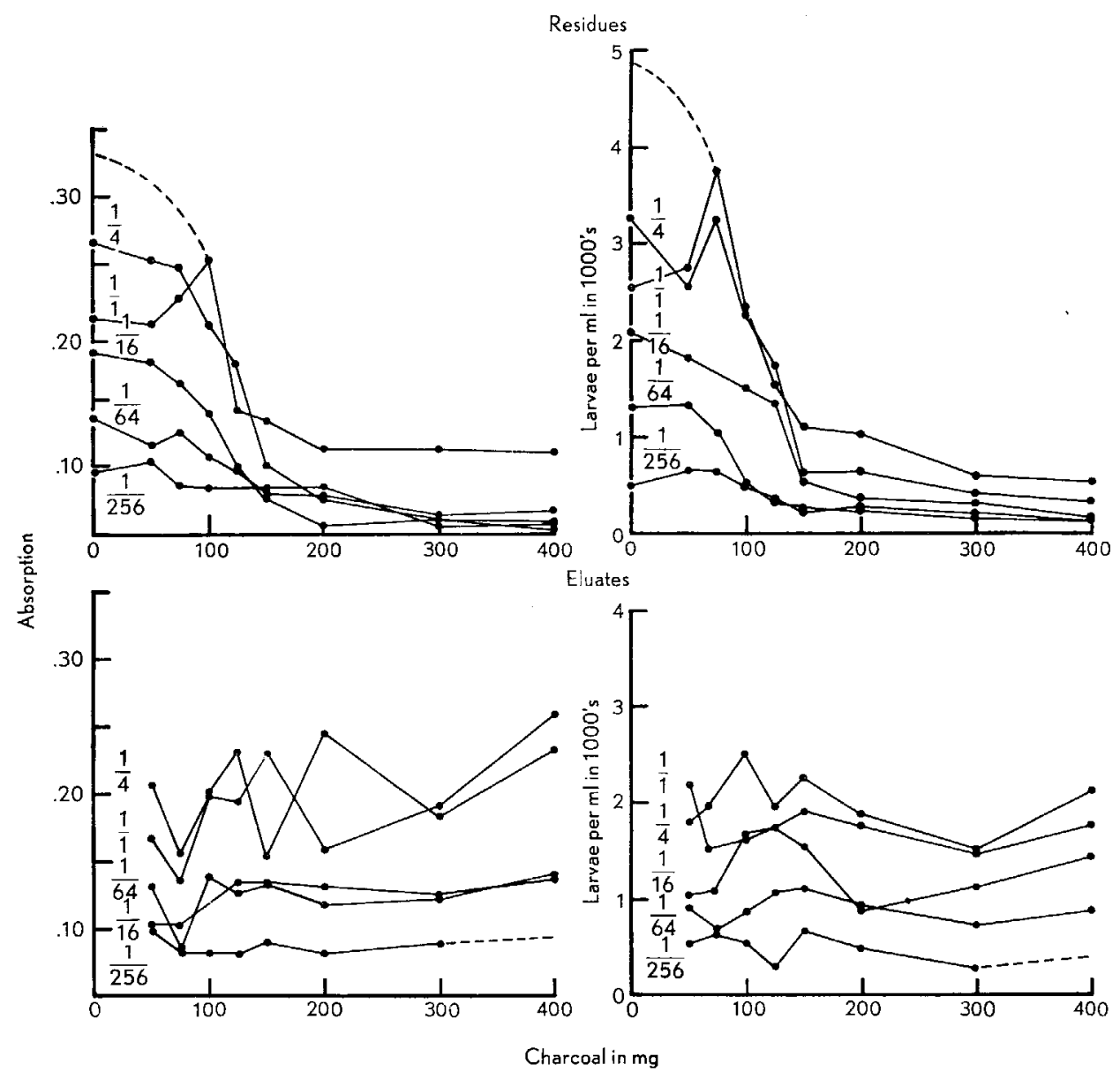

Fig. 8. Comparison of results from absorption and counting in assaying best weight of charcoal to use in the extraction of hatch factor from raw diffusate. Upper curves, residues after extraction with charcoal. Lower curves, eluates from charcoal. Left hand graphs, absorption. Right hand graphs, counts.

the hatch-dilution curve is asymptotic to the water hatch (Shepherd 1962). Fenwick (1952) fitted a straight line to the descending points of the curve and derived an arbitrary end point in terms of $\log$ dilution ( $\log$ activity or L.A.) where the straight line cuts the water hatch. Similarly arbitrary end points, A, B, and C in fig. 9 can be derived for the arithmetic, logarithmic and double logarithmic curves respectively, but all give different L.A. values. 
Fenwick (1952) found that straight lines fitted to the descending parts of hatch-dilution curves for diffusate of different strengths were more or less parallel for a given stock of cysts and diffusate. In bioassay work this assumption is often helpful in comparing the activity of different test substances derived from the same diffusate. Omidvar (1961) also found that hatch-dilution curves were parallel but Ellenby (1960) thought this need not always hold.

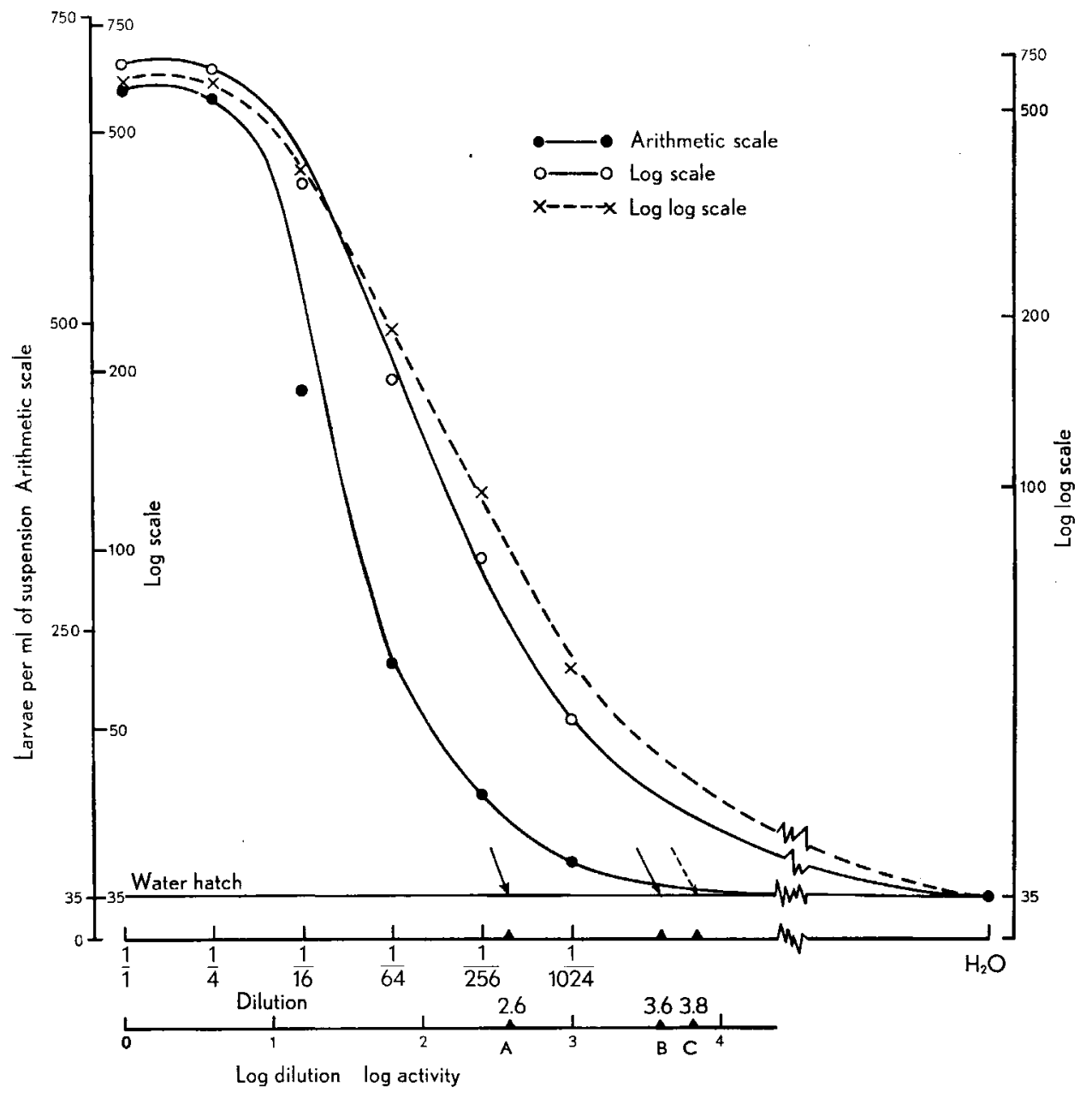

Fig. 9. Hatch dilution curves for 1959 cysts and 1960 diffusate. Each point is the mean hatch from 24 batches of 250 cysts. The hatch is plotted against dilution on arithmetic, logarithmic and double logarithmic scales which give different estimates (A, B \& C) of the Log Activity.

The curves in figs 6 and 7 appear to run parallel to each other where activity is high but not where it is low. Here only the right-hand tail of the curve remains (fig. 6, 150-400 $\mathrm{mg}$ charcoal) and Fenwick's arbitrary line cannot be drawn because there is no descending portion. L.A. values for products of low activity Nematologica VIII 
can therefore only be guessed. Where the design of the experiment lends itself as in fig. 8, L.A. values need not be obtained.

We thank Molly Spears and Margaret Mulcahy for technical assistance and A. J. Clarke for providing the test solutions.

\section{ZUSAMMENFASSUNG}

\section{Ein Versuch mit Heterodera spp. obne Zäblen von Zysten oder Larven}

Ein einfaches Gcrät beim Ansetzen von Zystenkulturen wurde durch Befestigen eines PlastikmaBes an das Ende einer einfachen Pipette erhalten. Die Larven werden absorptiometrisch gezählt. Mit dieser Methode wurde eine vollständige Prüfung ohne Zählen von Zysten oder Larven erzielt und somit viel Zeit und Arbeit gespart. Weitere Prüfungen mit grösseren Zystenmengen (etwa 250) und 5-fache Wiederholung wurden möglich. Die Ergebnisse stimmten gut mit denen überein, die durch Zählen erhalten wurden. Ellenby's Versuchsmethode mit nur 10 Zysten je Versuchsglas ergab in den meisten Fällen zu variable Ergebnisse. Die Transformation der Schlüpfwerte auf sine einfache oder doppelte logarithmische Skala gibt sigmaförmige Kurven, keine gerade Linien. Die log. Aktivitätswerte unterscheiden sich von denen aus untransformierten Zählungen. Die geraden Linien des abfallenden Teils der Schlüpf-Lösungskurven verlaufen parallel, wenn die Aktivität hoch ist. Bei geringer Aktivität können derartige Linien nicht aufgestellt werden, weil nur der untere Teil der Kurve erhalten wird. Zuweilen können die Ergebnisse auch benutzt werden, um Veränderungen in der Aktivität der Lösungen zu zeigen ohne Bestimmung des log. der Aktivität.

\section{REFERENCES}

BLAKE, C. D. (1958). A turbidimetric method for estimating the number of nematode larvae in a suspension. Proc. Linn. Soc. N.S.W. 83, 241-244.

Carroll, K. K. (1958). Purification and properties of eelworm hatching factors. Nematologica, 3, 197-204.

Carroll, K. K., Heyes, J. K., Johnson, A. W. \& Todd A. R. (1958). The potato eelworm hatching factor 7. Further methods of concentration of the factor. Nematologica, 3, 154-167.

Clarke, A. J. (1960). Biochemistry department. Ann. Rep. Roth. Exp. Sta. 1960, 107-114.

Ellenby, C. \& Gilbert, A. B. (1960). A convenient modification of the dilution hatching trial for the potato root eelworm, Heterodera rostochiensis Wollenweber. J. Helm. 34, 99-102.

FENwick, D. W. (1951). The use of a microbalance in putting up uniformly sized batches of Heterodera cysts for experiment. J. Helm. 25, 161-165.

- (1952). The bioassay of potato-root diffusate. Ann appl. Biol. 39, 457-467.

FENWICK, D. W. \& WIDDowSON, E. (1958), The conduct of hatching tests on cysts of the potatoroot eelworm, Heterodera rostochiensis Woll. J. Helm. 32, 125-134.

GoodeY, J. B. (1957). Laboratory methods for work with plant and soil nematodes. Tech. Bull No. 2. Min. Agric. Fish. Food. London. H.M.S.O. pp. 47.

JONES, F. G. W. (1954). First steps in breeding for resistance to potato root eelworm. Ann. app. Biol. 41, 348-353.

Korsten, L. H. J., Sieben, J. W. \& Voskuyl, K. (1953). A colorimetric determination of number of eelworms in suspension. Euphyitica 2, 135-138.

Omidvar, A. M. (1961). On the effect of root diffusates from Tagetes spp. on Heterodera rostochiensis Woll. Nematologica, 6, 123-129.

Shepherd, A. M. (1962a). Emergence of larvae from cysts of the genus Hetcrodera. Comm. Agric. But. Farnham Royal, England, 90 pp.

- (1962b). New blue R, a stain that differentiates between living and dead nematodes . Nematologica, 8 (in press).

Widdowson, E. \& Wiltshire, G. H. (1958). The potato-eelworm hatching factor. Ann. appl. Biol. 46, 95-101. 